\title{
Compressive testing of an early 20th century brick masonry pillar
}

\author{
Anastasios Drougkas • Pere Roca • \\ Climent Molins $\cdot$ Vicente Alegre
}

Received: 8 April 2015/Accepted: 15 June 2015

(C) RILEM 2015

\begin{abstract}
An experimental campaign involving the compressive testing of a brick masonry pillar extracted from a historical building is presented in this paper. The test procedure and the instrumentation are designed in order to determine, in addition to the compressive strength and global Young's modulus of the structure, the behavior in different parts of the pillar. Material samples, representative of the external leaf and the infill, are extracted from the pillar and tested in compression. Differences in strength and elasticity of the two components are critically presented and their influence on the maximum load and failure mode of the pillar are discussed. Finally, a simple analytical model is employed in order to quantify the effect of the mismatch of Young's modulus of the two components of the pillar. Analogies between the studied pillar and three-leaf wall masonry are drawn.
\end{abstract}

Keywords Brick masonry - Cement mortar . Compressive strength · Historical structures . Analytical modeling

A. Drougkas $(\bowtie) \cdot$ P. Roca $\cdot$ C. Molins

Departament d'Enginyeria de la Construcció, Universitat Politècnica de Catalunya, Campus Diagonal Nord,

Building C1, Jordi Girona 1-3, 08034 Barcelona, Spain

e-mail: anastasios.drougkas@upc.edu

V. Alegre

COTCA, Tuset 8, 08034 Barcelona, Spain

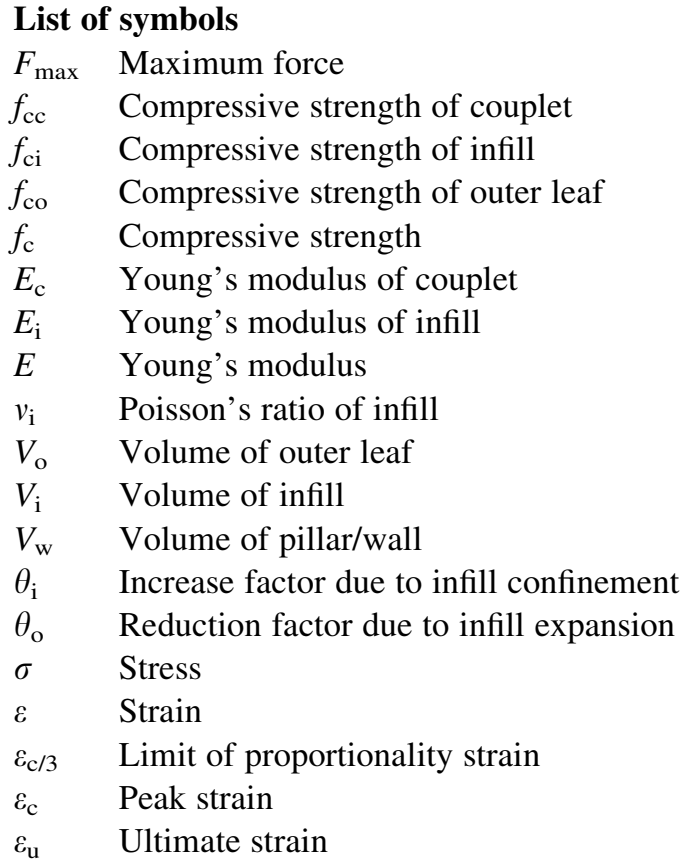

\section{Introduction}

\subsection{State of the art}

Brick masonry structural elements are abundant in historic buildings. Members composed of distinct parts with different mechanical properties, such as pillars with an infill core or multi-leaf walls, are 
characterized by the complexity of their response to structural loads. The need to preserve the historic and cultural value these buildings encapsulate requires the careful study of their mechanical behavior. The risk of damage due to earthquake events or the increase in loads imposed by adaptive reuse constitute great challenges to intervention design. The case of evaluation and design against high compressive loads is critical in avoiding long-term damage due to creep or brittle failure due to excessive loading.

Compression tests on masonry pillars, and specifically tests on pillars extracted from historical structures, are extremely rare. However, a number of tests on laboratory models simulating pillars in historical buildings can be encountered in the existing literature [1-5] or even full members extracted from existing buildings [6]. These tests have provided valuable information concerning the strength and the global elasticity of this type of structural members. In turn, the study of the failure modes has provided a better understanding of the resisting mechanisms and the applicability of repair or strengthening technologies.

In the context of structural intervention on existing buildings, good knowledge of the macroscopic structural characteristics of large masonry members is crucial. Analytical models for the prediction of the compressive strength of three-leaf masonry walls have been proposed relying on a quantification of the interaction of the leaves in masonry under compression [7]. Other models have been applied with a similar theoretical basis, but are mostly oriented towards the determination of the increase of strength due to grouting on the structure $[4,8]$. Such models could potentially be applied for the estimation of the compressive strength of masonry pillars composed of macroscopically distinct external leaves and infill.

\subsection{Motivation and objectives}

The opportunity to perform a compressive test on a pillar composed of entirely original material extracted from a historic structure arose during the inspection and restoration of a building in the Hospital Sant Pau complex in Barcelona. This particular test, as well as a number of other material tests which have been performed in parallel, is aimed towards investigating the global structural behavior of the pillar.

Given the fact that the structural typology and materials found in this building are encountered in several other parts of the hospital complex, the conclusions reached in this campaign may prove useful, at least as a first estimation, concerning the structural behavior and capacity of pillars in this and other neighboring buildings.

A damage survey was carried out on the visible surface of the structure. The results of the pillar compressive test are presented in detail, including numerous local and global deformation measurements. In addition, samples of the external leaf and of the infill extracted from the pillar were tested in compression. The compressive strength of these tests is compared to the compressive strength of the entire pillar, allowing for several conclusions to be reached concerning the influence of the properties of these two macroscopic components on the maximum attained stress. Finally, a simple analytical model is employed for the prediction of the behavior of the pillar in compression. The model is based on the macroscopic mechanical properties of the external leaf and the infill.

\section{Background}

\subsection{Building information}

The Hospital de Sant Pau building complex was commissioned in 1901 as a replacement of the older facilities located at the historical center of Barcelona. The Catalan modernist architect Lluís Domènech i Montaner was commissioned for designing and supervising the execution of the works, which stretched from 1901 to 1930 . The supervision of the works was assumed by his son, Pere Domènech i Roura, after 1920, when the second phase of the construction of the complex was initiated. It was under his supervision that the building in question was completed in a more moderate modernist style.

The project received significant support and funding. Innovative materials and structural techniques were employed, which included sophisticated thin tile masonry vaulting systems and extensive use of structural iron and cement based mortar. The building complex consists of individual buildings (pavilions) which kept the administrative and various medical functions each in its own space. The arrangement of the pavilions within the complex is shown in Fig. 1a.

Due to shifting and increasing operational and administration needs of the hospital, several pavilions 
underwent functional changes. Additionally, structural interventions, mostly in the form of the addition of secondary elements or load bearing steel and timber beams or partition walls, were carried out.

The entire complex constitutes an important landmark in Catalan Modernist architecture. It was awarded UNESCO World Heritage Site status in 1997. This has increased the visibility of and the public interest in the complex.

In 2008, shortly before the relocation of all medical facilities to a new neighboring building, the master plan for the structural restoration of the complex was compiled, the execution of which began the following year. The execution of the plan, as of 2015, has been almost entirely completed and includes strengthening and complete replacement of members.

\subsection{Inspection of the pillar}

The cylindrical pillar was initially located on the ground floor of the two-storey Toxicomania department building in the location indicated in Fig. 1b. In its initial state, the building, originally housing the kitchen facilities, was composed of a central nave and lateral aisles. At some point in the structure's history, steel profile columns were added at the center of the nave as additional supports for the expansion of the first floor. The arrangement of the pillars in the ground floor consists of a regular grid of similar masonry pillars and steel supporting columns. Therefore, the tributary area supported by the pillar, as defined after the addition of the steel columns, is a rectangular $4.67 \mathrm{~m} \times 3.34 \mathrm{~m}$ area.

The pillar supports a system of brick masonry arches and vaults. Before the beginning of intervention works, a slender masonry wall partition intersected the pillar. This wall was subsequently removed.

Following the removal of a large portion of the pillar, it was placed in a protective steel jacket padded with a neoprene sheet in order to facilitate moving and to avoid damage during transportation.

The total height of the sample was $1600 \mathrm{~mm}$ and had a diameter of $600 \mathrm{~mm}$. It was decided to test a portion with a height of $1000 \mathrm{~mm}$ in compression and to use the rest of the sample for extraction and further material testing. The removal and sectioning of the $600 \mathrm{~mm}$ portion of the pillar was performed using a diamond thread. Limitations of the available space between the load surfaces in the testing machine did not allow for a sample of a larger height to be tested.

The central part of the pillar is composed of solid clay bricks and Portland cement mortar. Its base is a solid stone foot and it is capped by a solid stone capital (Fig. 2a). The outer structure of the pillar resembles a Flemish bond arrangement of the bricks. Slight variations of the externally visible dimensions of the bricks and the mortar joints are encountered. Being composed of 42 brick courses, the portion of the pillar composed of brick and mortar masonry has a total height of roughly $3 \mathrm{~m}$. Measured along the perimeter, the "stretcher" bricks have an average length of roughly $280 \mathrm{~mm}$, the "header" bricks $90 \mathrm{~mm}$ and the (a)

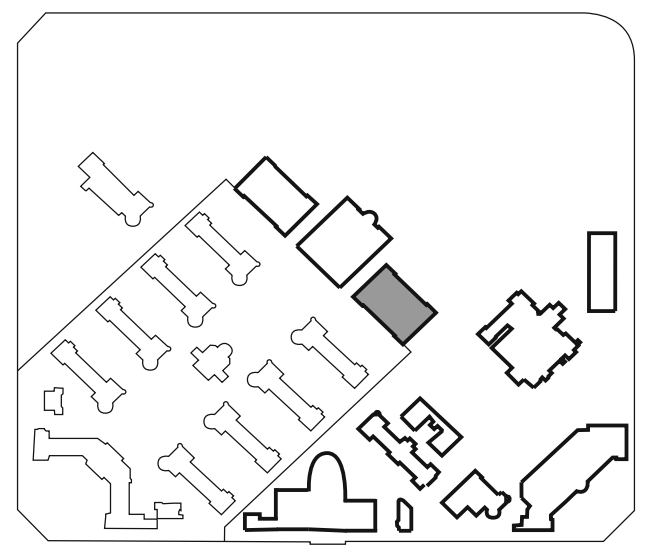

(b)

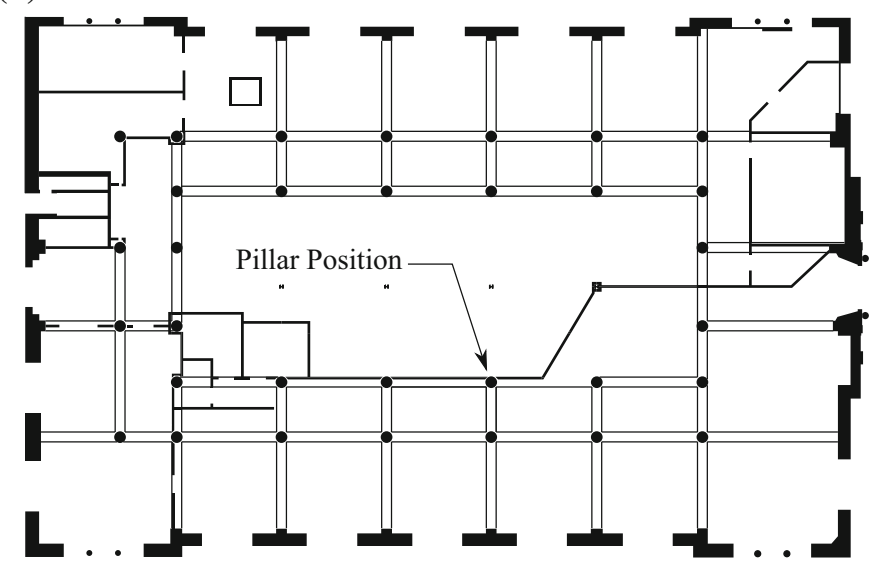

Fig. 1 a Location of the building inside the hospital complex. Buildings of the first phase in regular lines, of the second phase in tinted lines, with the toxicomania building grayed out. b Position of the pillar inside the building (ground floor plan) 
(a)

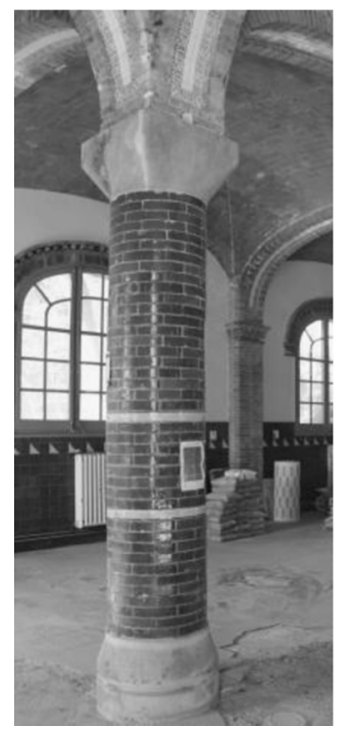

(b)

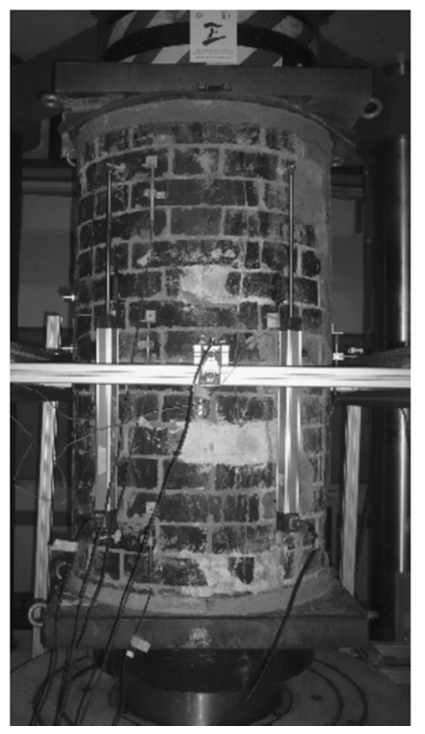

(c)

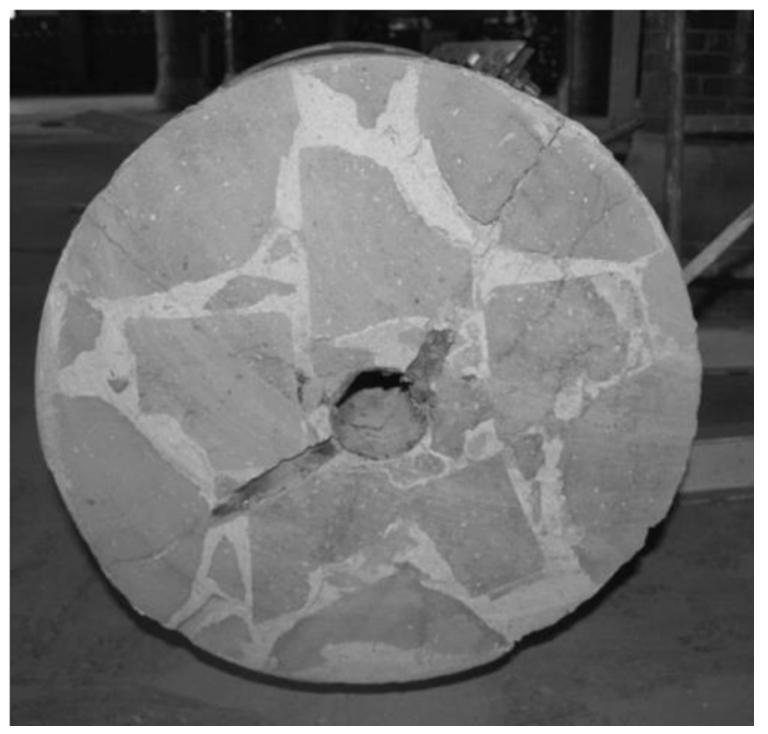

Fig. 2 a Original structural arrangement of the pillar, $\mathbf{b}$ its external and $\mathbf{c}$ its cross sectional geometry

"head" joints have a thickness of $5 \mathrm{~mm}$. The width of the stretcher bricks, which roughly corresponds to the width of the outer leaf of the pillar, is $140 \mathrm{~mm}$. The full circumference of the pillar is composed of 5 "stretcher" and 5 "header" bricks. The bed joints have a thickness of $7.5 \mathrm{~mm}$ and the bricks have a height of $60 \mathrm{~mm}$. The portion of pillar tested is composed of 16 brick courses and 15 bed joints (Fig. 2b).

While the exterior structure presents nearly complete regularity of the Flemish bond pattern, inspection of the cross sections, made visible by the diamond thread cuts, revealed a somewhat irregular internal structure, in which the "header" bricks are but a few centimeters thick. The "stretcher" bricks have more regular internal dimensions. The infill of the pillar is composed of 5 bricks of moderate dimensions and smaller brick fragments resembling a rubble masonry structure. The mortar, however, appears well compacted, although several voids were found (Fig. 2c).

The center of the pillar is vertically traversed by a drainage pipe with an external diameter of $90 \mathrm{~mm}$. The pipe appeared heavily corroded. The gross cross sectional area of the pillar is $282,743 \mathrm{~mm}^{2}$ and the net area, due to the central opening to accommodate the drainage pipe is $276,382 \mathrm{~mm}^{2}$, only $2.25 \%$ smaller than the gross area.

Visual inspection of the exterior surface of the pillar and the cross sections (Fig. 2) also revealed several structural defects in the bricks, local loss of material caused by what appears to have been anchored timber elements, a large spalling area near the base, significant corrosion of the drainage pipe located at the center of the pillar and, most importantly, three distinct vertical cracks running along the entire height of the specimen and separating it in three segments. Whether these vertical cracks are a result of the pipe corrosion, large sustained vertical loads or the structural interaction with the masonry walls with which it was in prolonged contact is unclear, although one of the cracks extended radially from a large vertical opening of the pipe. It is also not clear whether the steel profile columns were added as a remedy to this cracking. Additionally, while the exterior is composed of bricks of apparently the same type, several different types of bricks were identified in the interior, being recognized by a different color and cut texture.

\subsection{Preparation, instrumentation and test outline}

The bounding sections at the base and the top, which would serve as the load surfaces in the compression test, were initially rough and non-parallel. In order to overcome these defects so that good contact could be established with the load plates and in order to avoid premature localized damage during the test, high 
strength concrete caps were cast directly on the load surfaces. Additionally, $5 \mathrm{~mm}$ thick neoprene sheets were applied between the concrete caps and the load plates.

A large number of several types of instruments were used for the monitoring of the compression test. Given the rather uncommon nature of the test and the lack of an extensive literature on the subject, it was deemed necessary to attempt to gather as much information as possible. Given the large size, the irregular composition and damaged state of the structure, global measurements of vertical and horizontal deformation were deemed appropriate. However, properly arranged local measurements were not ruled out and may in fact provide insight into the global behavior of the structure (Fig. 3).

The global axial stiffness of the pillar is measured using three transducers measuring the vertical displacement along a large portion of the height of the pillar: L1, L2 and L3. Each of these transducers was placed in one of the three parts created by the three large vertical cracks. Therefore, they are not symmetrically distributed on the surface of the pillar. The instruments were fixed to the perimeter using small diameter pins attached in drilled holes.

Local vertical displacements were measured using 9 displacement transducers. These were arranged on three height levels and aligned horizontally where possible: T1, T2 and T3 near the top; M1, M2 and M3 at mid-height; B1, B2 and B3 near the base of the pillar. The purpose of this arrangement is the measurement of variation in local stiffness according to the position along the height of the pillar. A representative measurement length including two half bricks and one bed joint has been adopted. These instruments were too attached on the surface of the pillar using pins.

Four displacement transducers were used to measure horizontal movement in four points along the perimeter at the mid height of the pillar. These points were located at $90^{\circ}$ angle intervals and their measurements could be used to approximate the global radial expansion of the pillar under concentric compression. These instruments were fixed on a surrounding aluminum frame and oriented in a direction normal to the surface of the pillar.

Three strain gauges were used in alignment with the long vertical LVDTs. They were attached to the outer surfaces of three intact bricks using an adhesive resin. The intended purpose of the strain gauges is the measurement of the deformation of a single brick in order to estimate its modulus of elasticity.

The arrangement of the instruments is shown in Fig. 3, along with the existing damage documented through visual inspection. The anchoring areas of the timber elements are shown using small grayed-out rectangles. These defects are several centimeters in depth. The spalling area, though large, is not as deep. The distribution of the large vertical cracks and the location of the spalling area divide the pillar in three uneven segments: one part consisting of roughly half the
Fig. 3 Survey of existing damage on masonry pillar. Large vertical cracks and spalling area near the base are visible. Instrument placement on pillar: large vertical transducers (L), small horizontal transducers $(\mathrm{H})$, small vertical transducers at the top, middle and base (T, M, B), strain gauges $(\mathrm{G})$

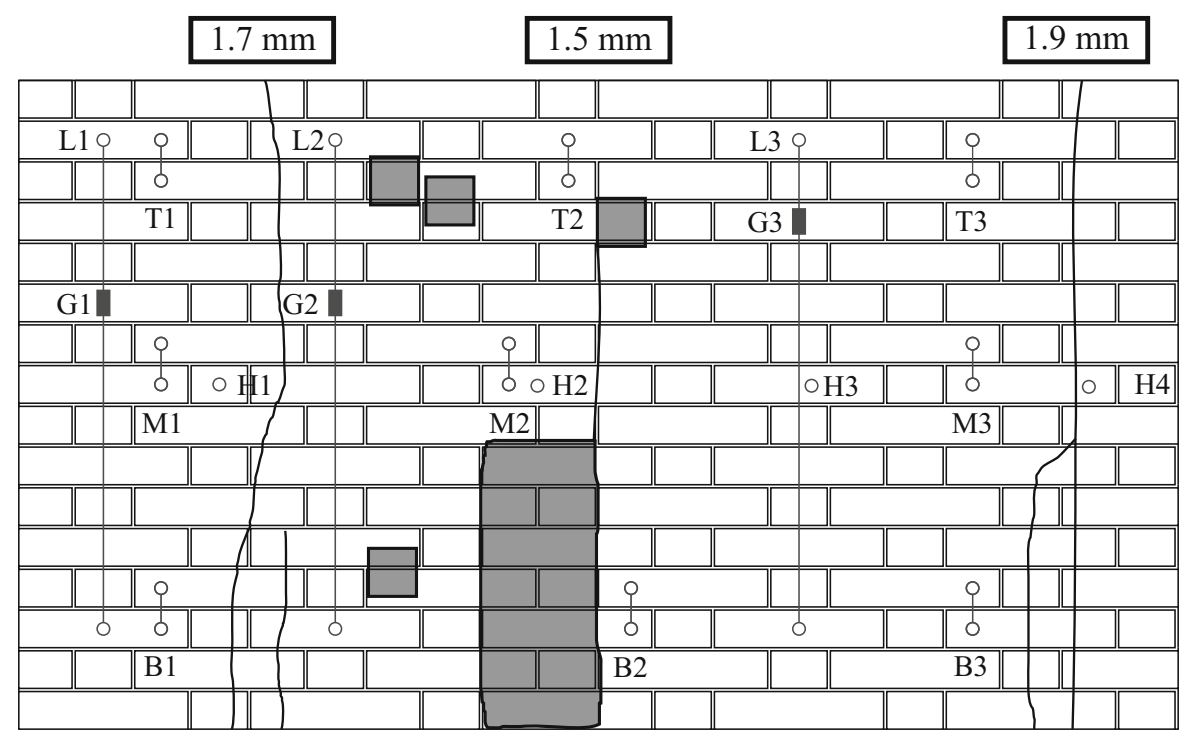


pillar and two parts consisting of roughly a quarter of the pillar each. This fact, along with the superficial damage, dictated the arrangement of the instrumentation.

Several load cycles were performed during the test. These consisted of two applications of $200 \mathrm{kN}$ at a load and unload rate of $0.2 \mathrm{~mm} / \mathrm{min}$ with the maximum load being maintained for $5 \mathrm{~min}$. An application of $400 \mathrm{kN}$ at a rate of $0.3 \mathrm{~mm} / \mathrm{min}$ followed, the maximum load again maintained for $5 \mathrm{~min}$. Subsequently, a load of $400 \mathrm{kN}$ at a rate of $0.5 \mathrm{~mm} / \mathrm{min}$ is again applied, held for $5 \mathrm{~min}$ at the maximum, and, finally, a steady load rate of $0.2 \mathrm{~mm} / \mathrm{min}$ is applied until failure of the pillar. Following attainment of the peak, the pillar is unloaded by lifting the load cell.

Due to the height/diameter ratio of the pillar, equal to roughly 1.6 , failure due to buckling can be ruled out. The monolithic behavior of the pillar, however, cannot be easily ascertained due to the presence of large vertical cracks which may, in effect, split the pillar in three independent parts. The concrete caps may assist in preventing or mitigating such a mode of response, but collapse should be governed by both local material failure and global failure mechanisms.

\section{Pillar test results}

The peak force attained was $1694 \mathrm{kN}$, corresponding to $6.0 \mathrm{~N} / \mathrm{mm}^{2}$ of compressive stress taking into account the gross area of the pillar. The elastic modulus of the pillar at $50 \%$ of the maximum load was $6075 \mathrm{~N} / \mathrm{mm}^{2}$. Throughout the application of the load and before the attainment of the maximum force, the variation of the elastic modulus was very small, potentially owing to the good compaction of the cement mortar in the joints and the prolonged submission to compressive loads in the original structure. The force-axial strain response curve, the strain having been calculated from the displacement measured at the large vertical transducers, is presented in Fig. 4a. Considering that the aspect ratio of height to diameter of the pillar is lower than 2 , which is deemed optimal for compressive testing, the actual compressive strength of the pillars in the real structure, with height to diameter ratio about 5 , may be even lower. The fact that the pillars in the actual structure are roughly 3 meters in height does not allow for a direct comparison of the compressive strength obtained in the experiment with that of the original pillars remaining in the building.

Figure $4 \mathrm{~b}$ illustrates the strain measurements from gauges G1, G2 and G3. According to these readings, the elastic modulus is equal to $7320 \mathrm{~N} / \mathrm{mm}^{2}$. Given the irregular structure of the pillar and the very short measurement length, this value only serves as an indicative measurement of the elastic modulus of the pillar. Furthermore, it is not certain that the stress in the brick is equal to the average vertical stress at the pillar, and should, therefore, not be considered indicative of the elastic modulus of the brick either.

The progression of damage was visually monitored during the test. At a load of $1000 \mathrm{kN}$ the large preexisting vertical cracks had expanded into the concrete caps and new vertical cracks had appeared on the surface. It is assumed that the preexisting cracks exhibited further opening. Near the maximum load, limited superficial spalling of bricks was registered, while the already large spalling area near the base had underwent further deterioration, including new cracks and spalls, although not to a significant extent.

Localized damage in the joints, such as vertical cracks in the head joints or crushed mortar in the bed joints was not noticed at close visual inspection. Furthermore, superficial damage in the bricks was mostly limited to "header" bricks, which are only a few centimeters thick at most points. Crushed material was not found to have fallen from the pillar in any significant amount from either the bricks or the joints. No cracks or other damage appears to have originated from the pins used for the anchoring of the measurement instruments. The concrete caps also did not appear to bear significant damage except near the edges. Removal of the concrete caps also revealed that no localized damage had been caused near the load surfaces.

This global failure appears to have developed mostly along the preexisting vertical cracks and resulted in separation of the three pillar segments. The new damage identified at the end of the test, along with the preexisting damage, is shown in Fig. 5. It is clearly indicated that most new vertical cracks originated near the anchor points of the old timber elements. These too extended to the concrete caps. No evidence of crushing damage was discovered externally in neither the bricks nor the joints and new vertical cracks were limited in number and expanse. 

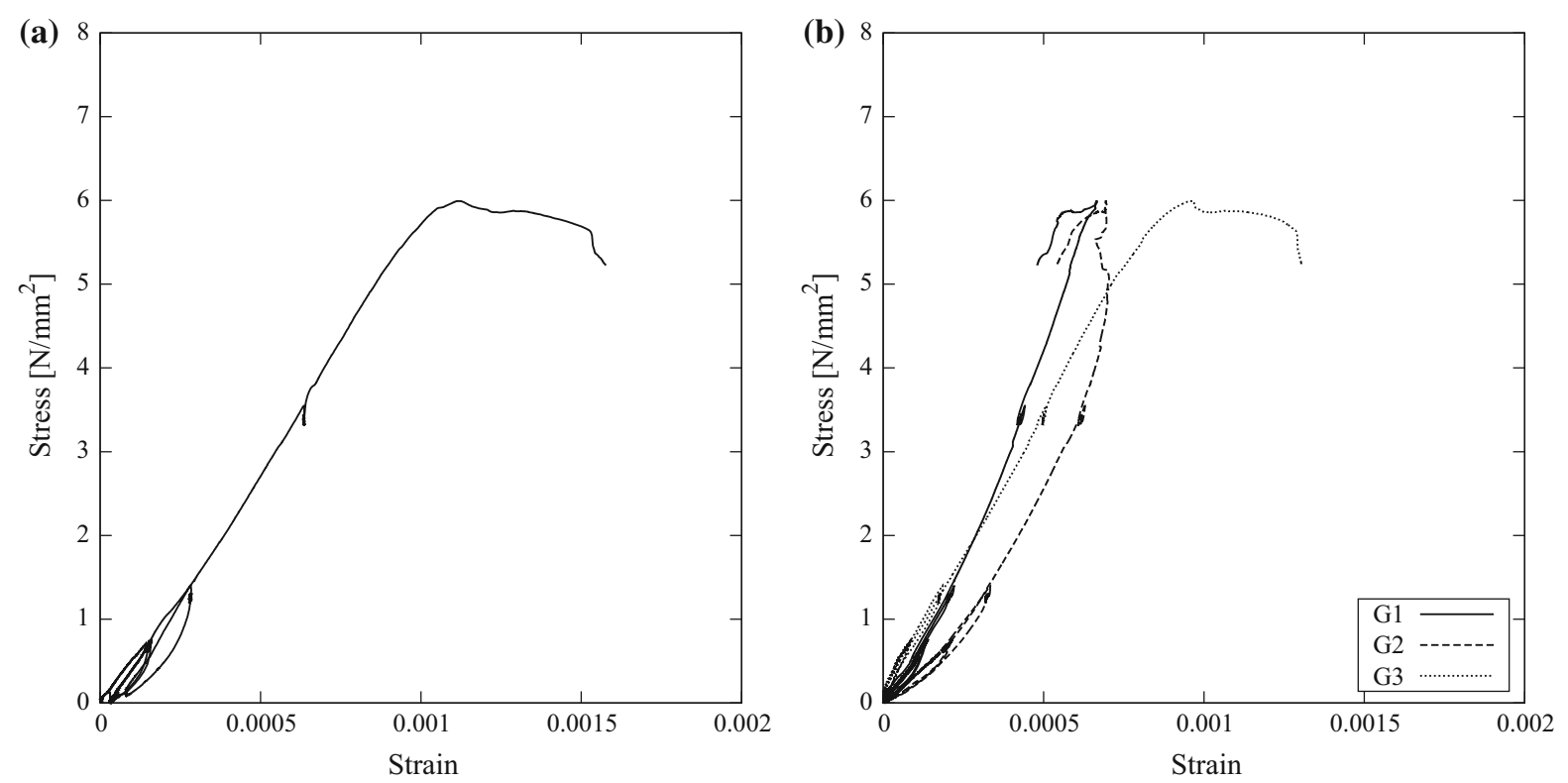

Fig. 4 Stress-axial strain curves: $\mathbf{a}$ transducers and $\mathbf{b}$ strain gauges

Fig. 5 Preexisting (solid lines) and new (dashed lines) damage at the end of the test

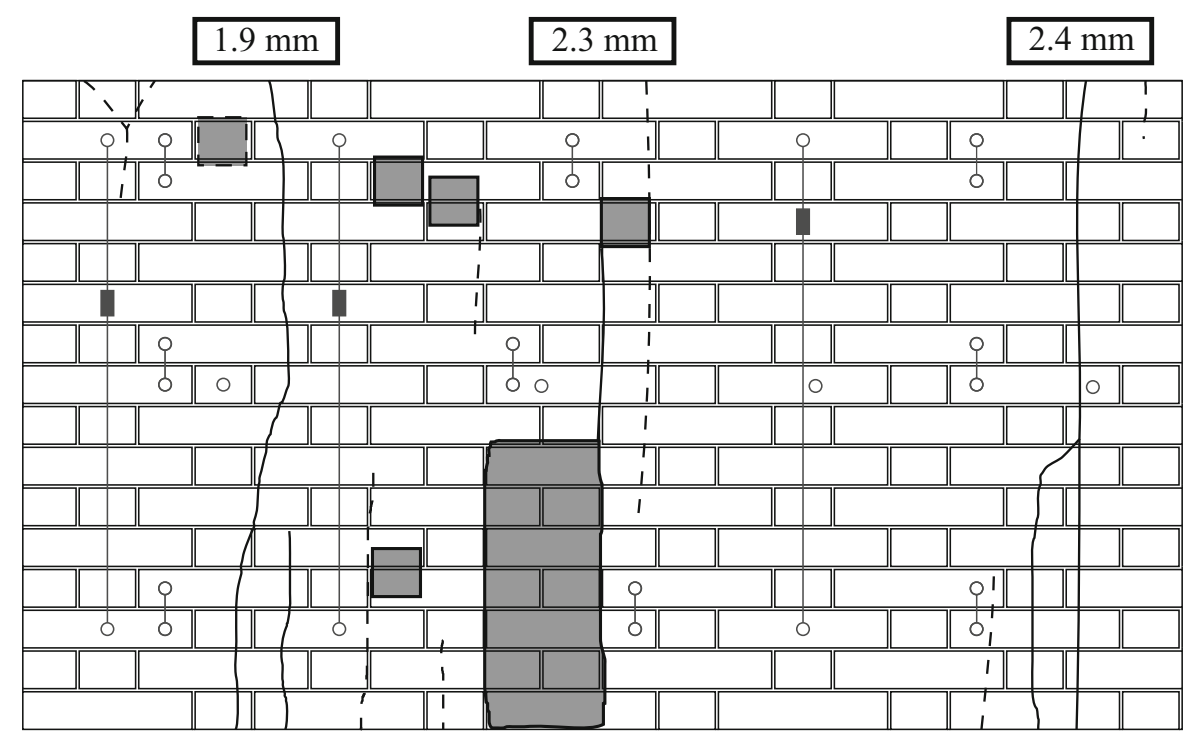

Whereas global axial stiffness, defined as the average stiffness derived from the large vertical transducers, was steady until failure, different values of stiffness were registered in each of the three masonry segments. Transducer L2 in particular showed a much smaller stiffness than L1 and L3, especially for low loads and for loads near failure, as can be seen in Fig. 6. The L2 transducer was placed near the large spalling area which may account for this behavior.

Another discrepancy was found in the behavior registered at different heights by the small vertical transducers, which is illustrated in Fig. 6a. The base transducers recorded a clearly nonlinear response near the peak, the middle transducers recorded an almost elastic unloading after the peak, as did top transducers 

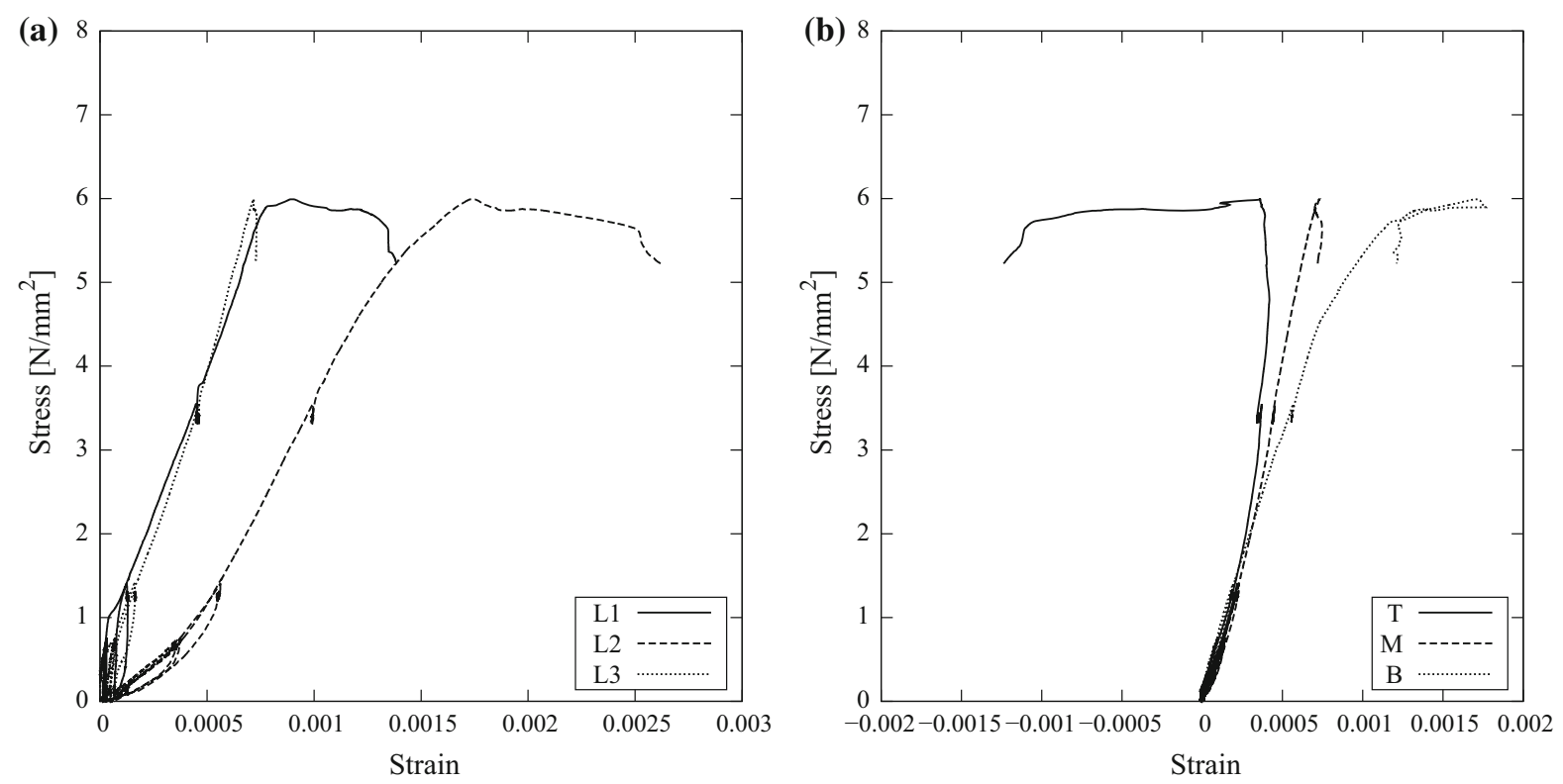

Fig. 6 a Force-displacement curves: a L1, L2 and L3 transducers and b average of top, middle and base transducers

following a sudden expansion after the unloading process started. At $50 \%$ of the maximum load the three top transducers registered an average stiffness of $13511 \mathrm{~N} / \mathrm{mm}^{2}$, the middle transducers $9196 \mathrm{~N} / \mathrm{mm}^{2}$ and the base transducers $6111 \mathrm{~N} / \mathrm{mm}^{2}$. However, the individual transducers at each level did not register the same stiffness, especially at the top part, where the maximum stiffness was $20252 \mathrm{~N} / \mathrm{mm}^{2}$ and the minimum was $7883 \mathrm{~N} / \mathrm{mm}^{2}$ at the T3 and T1 positions respectively, but the variation was much smaller for the other two levels.

Horizontal expansion was uneven in the two directions set by transducers $\mathrm{H} 1-\mathrm{H} 3$ and $\mathrm{H} 2-\mathrm{H} 4$, as shown in Fig. 7. Generally, the displacements were much larger in the $\mathrm{H} 1-\mathrm{H} 3$ direction. Considering the total radial expansion as the average produced by the two directions, the Poisson's ratio of the pillar reaches the value of 0.50 before $50 \%$ of the maximum load. The initial ratio for a load level of $300 \mathrm{kN}$ is 0.22 .

\section{Material sample extraction and test results}

The sampling methodology is based on the extraction of vertical cylindrical samples from the masonry. These samples may be used for the formation of cylindrical masonry couplets (two units and one intermediate mortar joint) and cylindrical infill samples. The height of the infill samples may be adjusted for compliance with the dimension ratios designated by testing standards with much more freedom than in the case of unit/mortar couplets. In the latter case size limitations may exist due to the height of the brick.

Extraction of masonry samples through drilling is only marginally disturbing to the masonry when performed with a sufficiently low spinning and advance velocity. The small size and regularity of the extracted samples alleviates the problems that may arise from attempting to extract entire units, which may crack during removal. Extraction of full units was not considered in the pillar under investigation due to the strong adherence of the cement mortar to the bricks.

Vertical coring generally requires access to the top of masonry members or the removal of large portions of masonry. This can be achieved in window openings, parapets or other members to which access can be achieved during strengthening, reconstruction or demolition works. In the particular, but common, case of single leaf walls, horizontal cores are arguably easier to extract. However, the interpretation of the results obtained from this type of samples is more challenging. Vertical cores allow for an easier differentiation of the behavior of the constituent materials of 

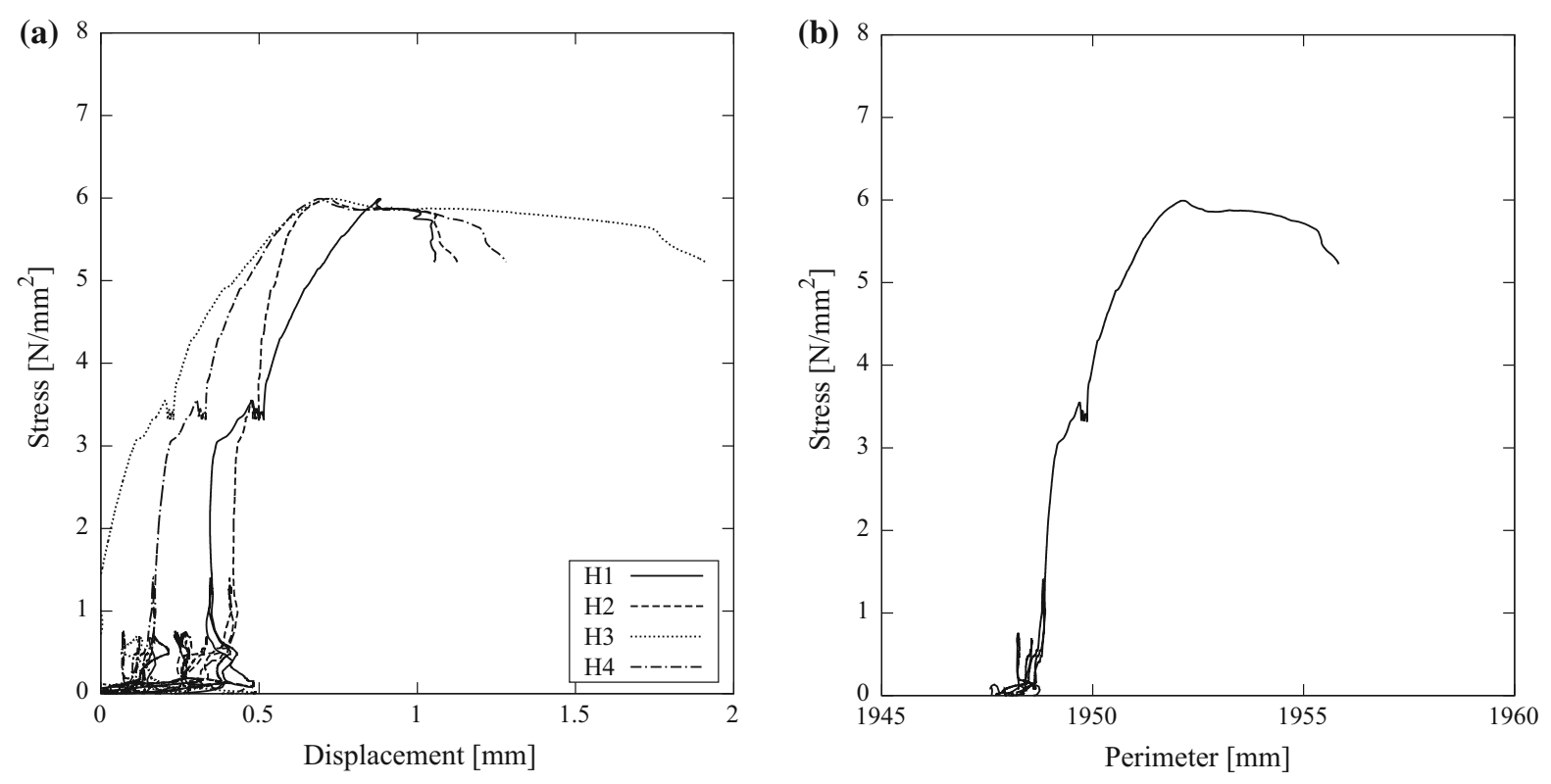

Fig. 7 a Horizontal transducer readings and $\mathbf{b}$ mid height perimeter change history

masonry. Furthermore, vertical coring allows the extraction of uniform samples, which can be subsequently subjected to a wide variety of tests, such as splitting of unit samples or shearing of couplets. Thus, efficient use of the extracted material may be achieved.

The part of the pillar which was removed prior to the compressive test on the member was used for sample extraction. It was cut in $300 \mathrm{~mm}$ high segments using a diamond thread. This allowed for an easier extraction of vertical cores, which were subsequently segmented into couplet and infill samples of the desired height.

The compression test on unit/mortar couplets is meant to provide a macroscopic measurement of the strength and elastic modulus of the outer leaves of the masonry pillar. It should not be considered a representative measurement of the compressive strength of the masonry composite or even of the outer leaf of the pillar itself. This is due to size effects and the accumulation of damage, imperfections and variation of mechanical parameters encountered in the full member.

The schematic of the test setup is shown in Fig. 8a. Three longitudinal LVDTs are attached to the load plates for the measurement of the axial deformation of the sample. The load surfaces of the samples were carefully polished prior to testing in order to provide planarity and good contact with the load plates. The load was applied in displacement control at a rate of $0.001 \mathrm{~mm} / \mathrm{s}$. A total of six samples were tested. Samples CC_1, CC_2 and CC_3 were tested monotonically and samples CC_4, CC_5 and CC_6 were subjected to 5 cycles of cyclic loading ranging from 5 to $25 \mathrm{kN}$.

The results are presented in Table 1. The typical failure mode of the samples is shown in Fig. 8b. The failure mode resembles that of cylindrical concrete samples subjected to compression: vertical cracks run along the height of the samples. The mortar joint does not appear to be failing in compression (no crushed material was discovered on close inspection) but rather acts as a very stiff and very strong barrier between the two units, with the vertical cracks continuing through the joint. Overall, the compressive strength of the samples did not exhibit significant scatter. The Young's modulus, however, presented a coefficient of variation of $49 \%$. Whereas the samples subjected to monotonic loading had equal compressive strength to the ones tested cyclically, the latter group of samples exhibited a Young's modulus lower by $25 \%$ on average but with lower result dispersion.

With an average sample height of $102.5 \mathrm{~mm}$, the samples have an average aspect ratio of 1.36 . 
(a)

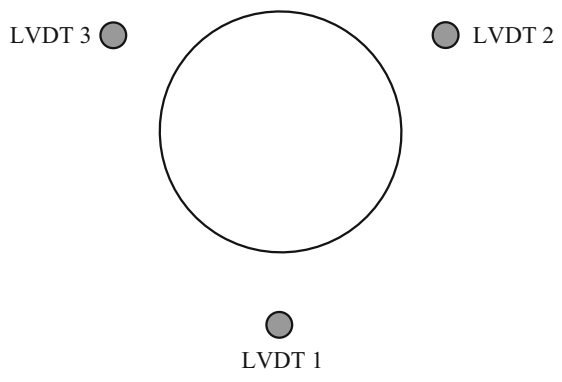

(b)

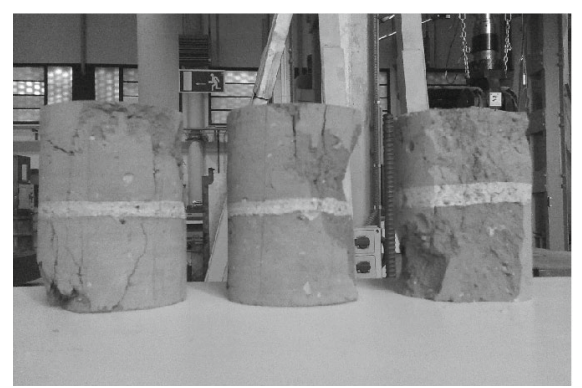

Fig. 8 a Schematic of test setup for unit/mortar couplet compression and $\mathbf{b}$ couplets after testing

Table 1 Unit/mortar couplet compression test results on $75.4 \mathrm{~mm}$ diameter cylinders
Coefficient of variation in parentheses

\begin{tabular}{lllll}
\hline Sample & Height $(\mathrm{mm})$ & $F_{\max }(\mathrm{kN})$ & $f_{\mathrm{cc}}\left(\mathrm{N} / \mathrm{mm}^{2}\right)$ & $E_{\mathrm{c}}\left(\mathrm{N} / \mathrm{mm}^{2}\right)$ \\
\hline CC_1 & 103.0 & 82.6 & 18.5 & 6092 \\
CC_2 & 102.0 & 58.9 & 13.2 & 1512 \\
CC_3 & 102.0 & 72.8 & 16.3 & 4836 \\
CC_4 & 103.0 & 71.0 & 15.9 & 4721 \\
CC_5 & 103.0 & 67.9 & 15.2 & 2299 \\
CC_6 & 102.0 & 66.1 & 14.8 & 2466 \\
Average & 102.5 & & $15.7(0.112)$ & $3554(0.494)$ \\
\hline
\end{tabular}

fixed module and a circumferential LVDT was placed at mid height for the determination of the Poisson's ratio (Fig. 9a).

The results are detailed in Table 2. The obtained values exhibited a dispersion higher than that achieved for the unit/mortar couplets. Additionally, a relatively low value of $7 \mathrm{~N} / \mathrm{mm}^{2}$ was registered for one of the samples. Also of note is the high average elastic modulus of the infill, which is higher than that of the unit/mortar couplets, even though the compressive strength was noticeably lower. The high percentage of cement mortar in the infill could account for this high stiffness. Additionally, the obtained Poisson's ratio is lower than the values typically encountered in clay bricks and cement mortar. A possible explanation is the high percentage of voids in the volume of the infill samples, which act as macroscopically observable pores in the medium. Finally, the post-peak behavior was scattered as well, with two of the samples exhibiting a very brittle response. The failure mode observed (Fig. 9b) is mixed and depends on the geometrical arrangement of the mortar and brick in the infill. Areas of crushed material were discovered, consisting of both brick and mortar, while vertical cracks mainly developed across the brick or the interface between the brick and the mortar. It is Three vertical LVDTs were placed on an externally 
Fig. 9 a Schematic of test setup for infill compression and $\mathbf{b}$ infill cylinders after testing (a)

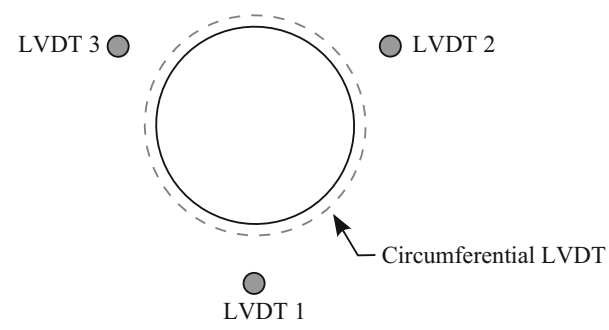

(b)

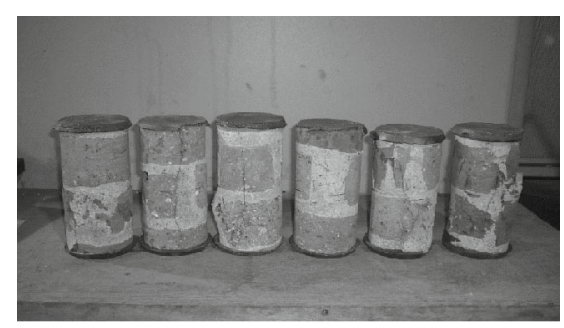

Table 2 Infill compression test results on $75.4 \mathrm{~mm}$ diameter cylinders

\section{Coefficient of variation in} parentheses

\begin{tabular}{llllll}
\hline Sample & Height $(\mathrm{mm})$ & $F_{\max }(\mathrm{kN})$ & $f_{\text {ci }}\left(\mathrm{N} / \mathrm{mm}^{2}\right)$ & $E_{\mathrm{i}}\left(\mathrm{N} / \mathrm{mm}^{2}\right)$ & $v_{\mathrm{i}}(-)$ \\
\hline IC_1 & 146.6 & 44.65 & 10.0 & 10,579 & 0.077 \\
IC_2 & 144.4 & 59.39 & 13.3 & 13,888 & 0.126 \\
IC_3 & 146.8 & 31.26 & 7.0 & 5241 & 0.130 \\
IC_4 & 136.9 & 50.01 & 11.2 & 8621 & 0.182 \\
IC_5 & 143.3 & 42.86 & 9.6 & 16,702 & 0.013 \\
Average & 143.6 & & $10.2(0.225)$ & $11,006(0.406)$ & $0.106(0.566)$ \\
\hline
\end{tabular}

arguable that the mortar in the infill has a lower strength than the mortar in the bed joints due to a lower amount of effective compaction. The load surface of the sulfur mortar cap was found undamaged after completion of the tests.

The stress-strain graphs obtained from both the couplets and the infill samples are presented in Fig. 10. In the former case, an initial adjustment of the load plate to the polished surface of the sample is noted. It results in an apparent increase in the Young's modulus of the sample at the beginning of the response followed by a linear part. It is assumed that the linear part is representative of the behavior of the material due to the polishing of the load surface, the high stiffness of the load plate and the aspect ratio of the samples. As the measurements during the infill sample testing were taken directly from the samples, this initial adjustment was not encountered.

It is immediately apparent that the compressive strength of the pillar is lower than the average compressive strength of either of its macroscopic components by a large margin.

\section{Analytical modeling}

Analytical models for the prediction of the compressive strength of three-leaf masonry have been proposed, mostly for the purpose of estimating the strength increase in injected members [4, 8]. The model proposed by Egermann and Neuwald-Burg in particular could potentially be applied in this case [7]. It is based on the compressive strength and the volume of the two leaves, the compressive strength of the wall being

$f_{\mathrm{c}}=\left(\frac{V_{\mathrm{o}}}{V_{\mathrm{w}}}\right) \theta_{\mathrm{a}} f_{\mathrm{co}}+\left(\frac{V_{\mathrm{i}}}{V_{\mathrm{w}}}\right) \theta_{\mathrm{i}} f_{\mathrm{ci}}$

where $V_{\mathrm{o}}, V_{\mathrm{i}}$ and $V_{\mathrm{w}}$ are the total volumes of the outer leaf, the infill and the member, and $f_{\text {co }}$ and $f_{\text {ci }}$ are the compressive strength of the outer leaf and infill respectively. The factors $\theta_{\mathrm{i}}$ and $\theta_{\mathrm{o}}$ are constants which represent the interaction of the leaves. The former is equal to or larger than 1 and indicates the increase in the compressive strength of the infill due to confinement by the outer leaf. The latter is equal to or lower than 1 and indicates the decrease in the strength of the outer leaf due to the expansion of the infill when compressed vertically. Both factors, empirically determined, describe an interaction process between an outer leaf much stronger and stiff than the infill. The expression may, therefore, be considered ill-suited to the present case. It does however offer a qualitative insight on the fact that failure of one component influences the bearing capacity of the other and can be tentatively used in the present case.

The volume distribution is considered to be $62 \%$ outer leaf, $35 \%$ infill and $2 \%$ voids, corresponding to 

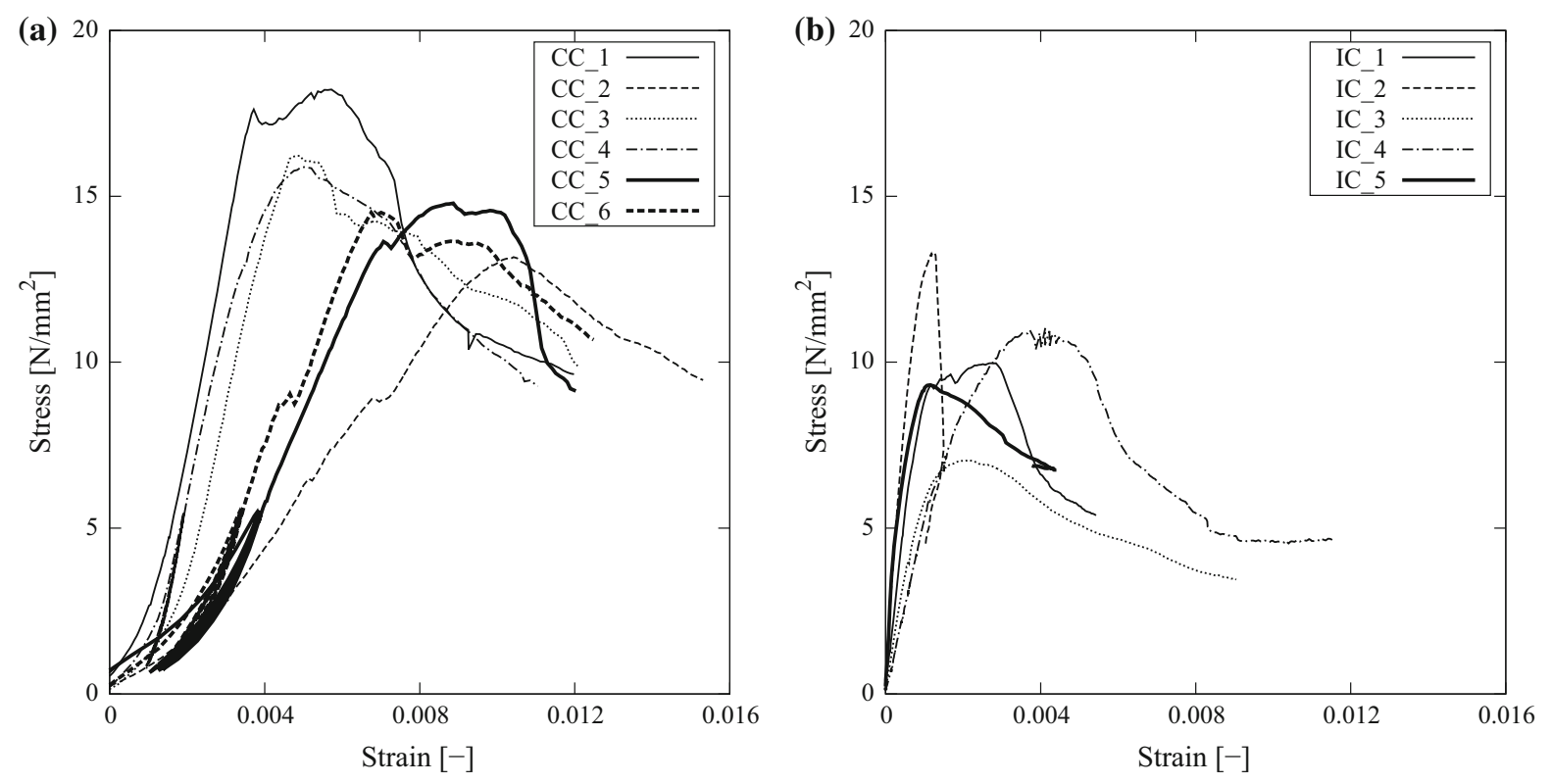

Fig. 10 Stress-strain graphs: a couplet compression test and $\mathbf{b}$ infill compression test

the central pipe. A factor of 1 is assumed for $\theta_{i}$, meaning that the inner leaf gains no increase in its compressive strength due to confinement from the outer leaf (a reasonable assumption for the infill given its high stiffness and strength). A factor of 0.67 is assumed for $\theta_{\mathrm{o}}$ as specified by Egermann and Neuwald-Burg, which represents the reduction of strength of the outer leaf due to bending caused by the lateral expansion of the infill. According to these assumptions, the derived compressive strength according to Eq. (1) is $9.85 \mathrm{~N} / \mathrm{mm}^{2}$, noticeably higher than the experimentally derived value.

An alternative simple analytical model, which employs the stress-strain curves of the outer leaf and the infill, may be employed in order for the behavior of the pillar in vertical compression to be better understood. The model is based on the assumption that under vertical compression the outer leaf and the infill, which are modeled as the two mesoscopic components of the pillar loaded in parallel, function in perfect composite behavior and, therefore, are subjected to the same strain. Disregarding tensile damage to the components, the effect of existing damage and the lateral expansion of the leaves when yielding in compression (being equivalent to having a Poisson's ratio equal to 0 ) the behavior of the pillar can be idealized by assuming that a part of the cross section behaves like the outer leaf, a part of it as the infill and a final part as the central void that does not bear any stress. Overall, the macroscopic division of the pillar in an outer leaf and an infill resembles the similar discretization made for three leaf masonry with a rubble infill.

The mechanical properties as determined in the already presented material tests are used for the macroscopic representation of the two components. The global stress is calculated as the weighted average of the components, contributing according to their cross section size compared to the gross cross section of the pillar. Due to the different elastic characteristics of the two components, the peak stress is reached at different strain levels for each material.

For the simulation of the two components in compression a parabolic curve will be used to represent their behavior [10]. According to this curve the limit of proportionality is reached for a compressive stress equal to $1 / 3$ of the compressive strength. The strain at that point is equal to

$\varepsilon_{\mathrm{c} / 3}=-\frac{1}{3} \frac{f_{\mathrm{c}}}{E}$

The compressive strength is reached for the peak strain equal to 
$\varepsilon_{\mathrm{c}}=-\frac{5}{3} \frac{f_{\mathrm{c}}}{E}=5 \varepsilon_{\mathrm{c} / 3}$

The ultimate strain $\varepsilon_{\mathrm{u}}$ is adjusted to fit the experimental data for each component. The parabolic curve of the compressive stress $\sigma$ is expressed as a function of the strain $\varepsilon$ as follows.

$\sigma(\varepsilon)=\left\{\begin{array}{cl}-f_{c} \frac{1}{3} \frac{\varepsilon}{\varepsilon_{c / 3}} & \text { if } \varepsilon_{c / 3}<\varepsilon \leq 0 \\ -f_{c} \frac{1}{3}\left(1+4\left(\frac{\varepsilon-\varepsilon_{c / 3}}{\varepsilon_{c}-\varepsilon_{c / 3}}\right)-2\left(\frac{\varepsilon-\varepsilon_{c / 3}}{\varepsilon_{c}-\varepsilon_{c / 3}}\right)^{2}\right) & \text { if } \varepsilon_{c}<\varepsilon \leq \varepsilon_{c / 3} \\ -f_{c}\left(1-\left(\frac{\varepsilon-\varepsilon_{c}}{\varepsilon_{u}-\varepsilon_{c}}\right)^{2}\right) & \text { if } \varepsilon_{u}<\varepsilon \leq \varepsilon_{c} \\ 0 & \text { if } \varepsilon \leq \varepsilon_{u}\end{array}\right.$ at Fig. 12 is obtained. The initial elastic stiffness is identical to the experimentally derived value. The global compressive stress reaches a local maximum of $7.7 \mathrm{~N} / \mathrm{mm}^{2}$ before reaching a secondary peak of $9.3 \mathrm{~N} / \mathrm{mm}^{2}$ at the strain coinciding with the peak stress of the outer leaf.
The basic parabolic curve is shown in Fig. 11a. The properties used in the application of the model are presented in Table 3 . The resulting curves for each material are shown in Fig. $11 \mathrm{~b}$.

The geometric distribution of the volume of the infill and the outer leaf is the same as in the Egermann model. By summing the contribution of each part to the global stress in the cross section, the curve shown

(a)

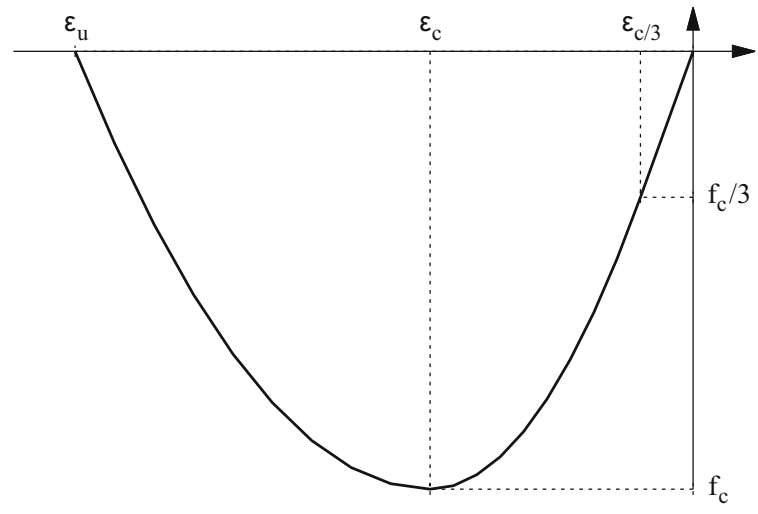

The initial local maximum is relatively close to the experimentally derived value, despite the simplicity of the model, and more accurate than the result of the Egermann and Neuwald-Burg model. Furthermore, the maximum stress in the experiment was reached at roughly the strain corresponding to the maximum stress in the infill. This suggests that failure of the pillar is governed by the concentration of stress in the infill

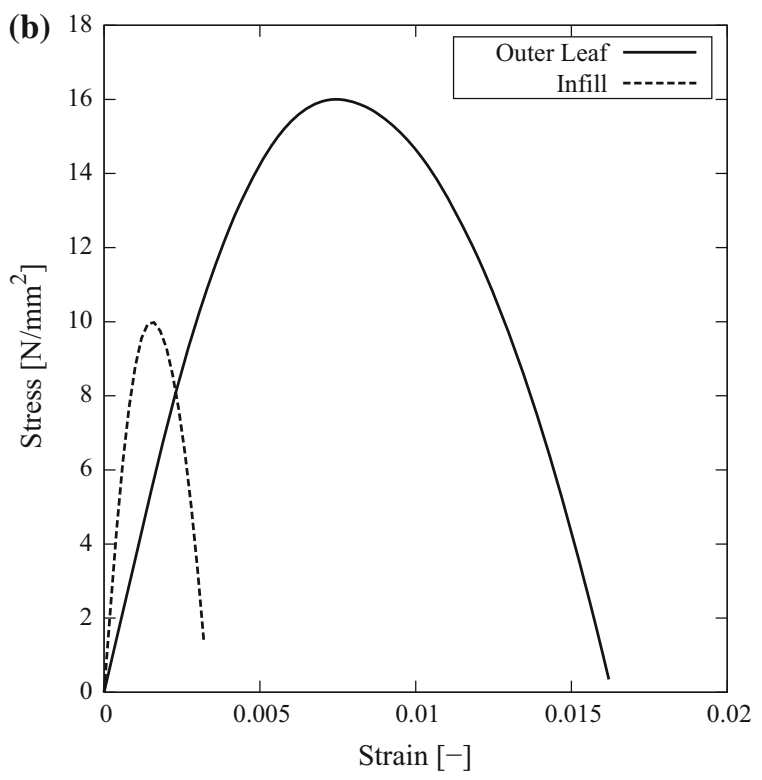

Fig. 11 a Basic parabolic curve used for analytical model. b Curves in compression for components used for analytical modeling 
Table 3 Material properties used in the analytical model

\begin{tabular}{llcl}
\hline Material & $f_{\mathrm{c}}\left(\mathrm{N} / \mathrm{mm}^{2}\right)$ & $E\left(\mathrm{~N} / \mathrm{mm}^{2}\right)$ & $\varepsilon_{\mathrm{u}(-)}$ \\
\hline Outer leaf & 16 & 3600 & 0.0165 \\
Infill & 10 & 11,000 & 0.0034 \\
\hline
\end{tabular}

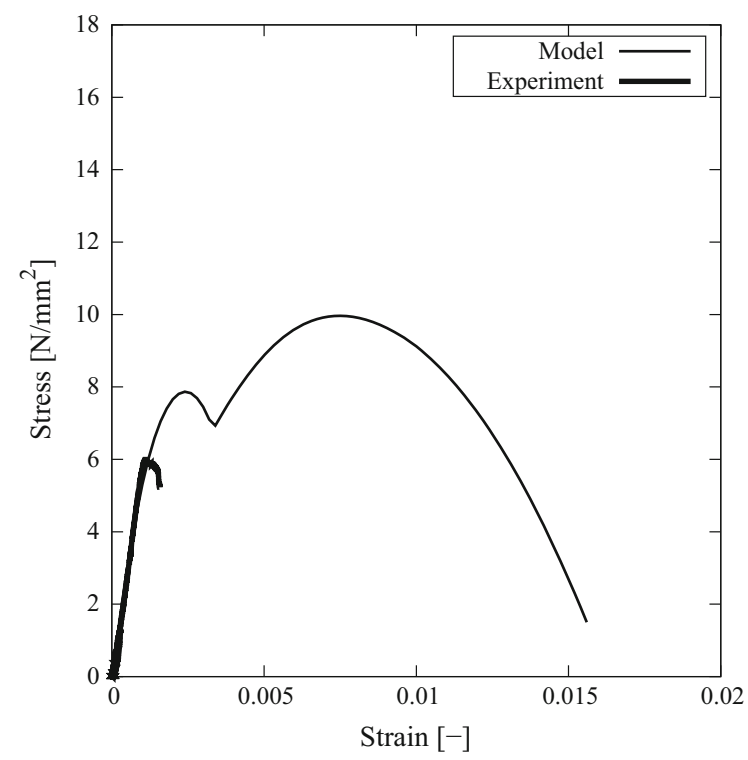

Fig. 12 Comparison of analytical model curve with experimental curve

and its consequent yielding in compression. Several parameters not considered in this analysis could cause a reduction of the maximum stress. These include the existing damage and imperfections in the pillar, tensile damage in the components, the interaction of the components after the onset of compressive damage and the non-perfect bond between the outer leaf and the infill, which may result in local shear slipping and tensile opening of interface cracks. However, the same overall conclusion is reached: the combined effect of low strength, high stiffness and brittle post-peak behavior of the infill may be detrimental to the global response of the pillar in compression.

The model employed here demonstrates that for this case the study of the compressive behavior of the pillar should be performed by taking into account the stressstrain behavior of the two macroscopic components and not merely their peak compressive stress. Further refinement of the model can be envisaged so that the interaction between the components can be more accurately represented, such as the reduction of the strength of the outer leaf due to bending.

\section{Conclusions}

A masonry pillar removed from a historical building is tested in concentric compression. The cylindrical element is composed of solid clay bricks, cement mortar and an infill core. Material extracted from the pillar using coring was tested as well in compression. The pillar corresponds to a structural typology in wide use in the building complex in which it was originally located and its constituent materials are also found in the same building and its neighboring structures in the complex.

The experimentally derived compressive strength of the pillar is lower than that of any of its macroscopic constituent materials, designated as the outer leaf and the infill. This may be attributable to the scatter of the compressive strength and ductility of the materials (especially the infill), size effects and the effect of existing damage. The interaction of the macroscopic components is also an important factor due to their different elastic characteristics.

A simple analytical model was able to highlight the main structural characteristics of the pillar which affect its behavior in compression. It is based on the compressive strength and Young's modulus of the macroscopic components of the pillar: the outer leaf and the infill. It provides more accurate results for this case than an analytical model based on the peak stress of the components.

The material extraction and testing methodology followed is applicable to a variety of masonry structures and presents a sound basis for the structural evaluation of existing structures and their simulation using micro-models.

Acknowledgments This research has received financial support from the Ministerio de Economía y Competitividad, through the research project MICROPAR (Identification of mechanical and strength parameters of structural masonry by experimental methods and numerical micro-modeling, Ref num. BIA2012-32234) and the ERDF (European Regional Development Fund).

\section{References}

1. Aiello MA, Micelli F, Valente L (2007) Structural upgrading of masonry columns by using composite reinforcements. J Compos Constr 11:650-658

2. Aiello MA, Micelli F, Valente L (2009) FRP confinement of square masonry columns. J Compos Constr 13:148-158 
3. Aprile A, Benedetti A, Grassucci F (2001) Assessment of cracking and collapse for old brick masonry columns. J Struct Eng 127:1427-1435

4. Valluzzi MR, Da Porto F, Modena C (2004) Behavior and modeling of strengthened three-leaf stone masonry walls. Mater Struct 37:184-192

5. Vintzileou EN, Miltiadou-Fezans A (2008) Mechanical properties of three-leaf stone masonry grouted with ternary or hydraulic lime-based grouts. Eng Struct 30:2265-2276

6. Almeida C, Guedes JP, Arêde A, Costa CQ, Costa A (2012) Physical characterization and compression tests of one leaf stone masonry walls. Constr Build Mater 30:188-197
7. Egermann R, Neuwald-Burg C (1994) Assessment of the load bearing capacity of historic multiple leaf masonry walls. In: Proceedings of the 10th international brick block masonary conference, pp 1603-1612

8. Vintzileou EN (2011) Three-leaf masonry in compression, before and after grouting: a review of literature. Int J Archit Herit 5:513-538

9. ASTM. ASTM C42/C42M-13 (2013) Standard test method for obtaining and testing drilled cores and sawed beams of concrete. ASTM International

10. Feenstra PH, De Borst R (1996) A composite plasticity model for concrete. Int J Solids Struct 33:707-730 